\title{
PERSEPSI WISATAWAN EROPA TERHADAP KUALITAS PELAYANAN RESEPSIONIS DI DESA MUNDUK, BULELENG, BALI
}

\author{
Made Handijaya Dewantara \\ Email: made.handijaya@pmbs.ac.id \\ UNIVERSITAS PRASETIYA MULYA
}

\begin{abstract}
This study aims to find out how European tourists generally perceive the quality of reception services in Munduk Village, Buleleng, Bali and to find out how European tourists perceive the quality of service that people provide in various types of hotel accommodations that are located in Munduk. This research is kind of quantitative-qualitative type, using four data collection techniques, namely interviews, questionnaires, document studies, and observations. Through descriptive analysis, five conclusions were obtained, among others: (1) guests' perceptions of service in tourist accommodation in Munduk are still in poor condition; (2) reliability and tangible aspects become the most highlighted aspects in the five indicators of the quality of reception services in Munduk; (3) Most customer complaints are caused by weak hospitality management processes carried out by accommodation owners, so that receptionists need to be given further training; (4) Accommodation owners and accommodation managers should develop a working mechanism with a job description and SOP (standard operational procedure); and (5) accommodation owners should collaborate with tourism stakeholders in Munduk, both the government, travel agents (offline and online), tourists, to academics.
\end{abstract}

Keywords: Perception, Tourists, Europe, Receptionist, Munduk

\begin{abstract}
Abstrak
Penelitian ini bertujuan untuk mengetahui bagaimana persepsi wisatawan Eropa terhadap kualitas pelayanan resepsionis di Desa Munduk, Buleleng, Bali, pada umumnya, serta untuk mengetahui bagaimana persepsi wisatawan asal Eropa terhadap kualitas layanan yang masyarakat berikan di berbagai jenis akomodasi perhotelan, yang berada di Desa Munduk, pada khususnya. Penelitian ini berjenis kuantitatif-kualitatif, dengan menggunakan empat teknik pengumpulan data, yaitu wawancara, kuesioner, studi dokumen, dan observasi. Melalui analisis deskriptif, diperoleh lima poin kesimpulan antara lain : (1) persepsi tamu tentang
\end{abstract}


pelayanan di akomodasi wisata yang terdapat di Munduk masih berada pada kondisi yang kurang baik.; (2) aspek reliability dan tangible menjadi aspek yang paling menjadi sorotan dalam lima indikator kualitas pelayanan resepsionis di Munduk.; (3) Sebagian besar keluhan pelanggan disebabkan oleh lemahnya proses manajemen hospitality yang dilakukan pemilik akomodasi, sehingga resepsionis perlu untuk diberikan pelatihan lebih lanjut.; (4) Pemilik akomodasi dan pengelola akomodasi hendaknya menyusun mekanisme kerja berikut dengan deskripsi kerja (job description) serta SOP (standard operational procedure); serta (5) pemilik akomodasi seharusnya berkolaborasi dengan para stakeholder pariwisata di Munduk, baik pemerintah, agen perjalanan (offline dan online), para wisatawan, hingga akademisi.

Kata Kunci: Persepsi, Wisatawan, Eropa, Resepsionis, Munduk

\section{Pendahuluan}

Kemajuan industri pariwisata di Indonesia dan Bali semakin pesat dari tahun ke tahun. Industri pariwisata telah menjadi sektor ekonomi unggulan (leading sector of economy) yang posisinya setara dengan komoditas lain, seperti tambang, manufaktur, dan kelapa sawit. Faktafakta menunjukkan betapa pentingnya posisi Bali sebagai destinasi wisatawan mancanegara ke Indonesia. Berdasarkan data 10 besar pasar utama pariwisata Bali tahun 2012 tercatat di antaranya 2 negara Eropa, yakni Perancis dan Inggris.

Namun, fakta di lapangan menunjukkan adanya ketimpangan. Kunjungan wisatawan asing yang berkunjung ke Bali, ternyata sebagian besar masih menyasar daerah Bali Selatan terlihat data statistik oleh Diparda Bali tahun 2015 bahwa turis sebagian besar mengunjungi Badung yakni $43 \%$ dan Denpasar 14\%, sedangkan daerah lainnya di bawah $10 \%$. Pilihan wisatawan terhadap Bali Selatan ini tentunya tidak terlepas dari menimbang dari kualitas pelayanan dan akomodasi di destinasi tersebut. Tidak bisa dipungkiri, lengkapnya fasilitas dan infrastruktur pariwisata menjadi daya dukung dalam referensi wisatawan untuk memilih destinasinya, sedangkan pengembangan kepariwisataan oleh pemerintah 
daerah hanya berfokus kepada Bali Selatan, sehingga ada banyak destinasi lain yang sebenarnya berpotensi namun belum digarap secara lebih optimal.

Pariwisata berbasis kerakyatan sering dipandang sebagai tonggak kesuksesan pariwisata yang berkelanjutan. Keterlibatan masyarakat lokal terbukti mampu menyelaraskan sinergitas dampak sosial, ekonomi dan lingkungan, antara kondisi terdahulu dan masa yang akan datang. Desa Munduk berlokasi di Bali Utara dan juga ikut mengusung konsep pariwisata berbasis kerakyatan.

Hingga saat ini, kunjungan wisatawan ke Desa Munduk sebagian besar didominasi oleh wisatawan asal Eropa. Tendensi asal wisatawan ini diperkirakan disebabkan oleh adanya pergeseran karaketristik wisatawan yang semakin jenuh dengan euforia dan hiruk-pikuknya Bali Selatan yang padat dengan turis. Namun, sangat disayangkan Desa Munduk masih belum mampu sejajar dan menjadi magnet untuk menarik wisatawan. Ada beberapa hal berkaitan dengan kualitas pelayanan yang dirasa masih kurang sesuai dengan harapan wisatawan Eropa, sehingga masih menjadi pertimbangan bagi turis untuk berkunjung. Oleh karena itu, sangat diperlukan sebuah studi untuk menggali persepsi wisatawan asal Eropa terhadap layanan resepsionis di akomodasi wisata di Desa Munduk, sehingga dapat diketahui dan dianalisis lebih mendalam letak kekurangan serta elemen yang perlu ditingkatkan sebagai upaya dalam meningkatkan kunjungan wisatawan Eropa ke Desa Munduk.

Resepsionis dipandang menjadi objek penelitian yang cukup penting mengingat posisi ini adalah posisi yang cukup krusial di dalam bisnis akomodasi perhotelan. Di Desa Munduk yang notabene industri akomodasi masih didominasi oleh biaya pribadi, seringkali dikelola secara non profesional, resepsionisnya berasal dari masyarakat sekitar yang tidak memiliki pengetahuan dibidang resepsionis. Hal ini berimplikasi kepada 
rendahnya mutu layanan yang diperoleh wisatawan. Ibarat sebuah negara, resepsionis merupakan duta utama dari sebuah hotel, karena turis yang datang menginap akan bertemu resepsionis di awal kedatangannya.

Berdasarkan latar belakang yang telah dipaparkan, maka dapat dirumuskan permasalahannya sebagai berikut: bagaimana persepsi wisatawan Eropa terhadap kualitas pelayanan resepsionis di akomodasi perhotelan di Desa Munduk, Buleleng, Bali? Secara umum penelitian ini bertujuan untuk bagaimana persepsi wisatawan Eropa terhadap kualitas pelayanan resepsionis di Desa Munduk, Buleleng, Bali. Tujuan khusus penelitian ini adalah untuk mengetahui bagaimana persepsi wisatawan asal Eropa terhadap kualitas layanan yang masyarakat berikan di berbagai jenis akomodasi perhotelan, yang berada di Desa Munduk.

\section{Tinjauan Pustaka}

Penelitian ini menggunakan tiga buah penelitian mengenai pelayanan resepsionis sebagai rujukan. Penelitian pertama ditulis oleh Saputro (2014), yang meneliti mengenai aktivitas resepsionis dalam menangani tamu personal di Ameera Boutique Hotel Yogyakarta. Penelitian ini berjenis deskriptif kualitatif dengan mengambil lokasi hanya pada satu buah hotel bisnis di daerah Yogyakarta. Ruang lingkup penelitian dibatasi hanya kepada aktivitas layanan yang dilakukan oleh resepsionis, dan dengan mengambil informan yang lebih spesifik yaitu hanya kepada tamu-tamu personal (atau dalam praktek industrinya sering disebut tamu individual). Selain mengambil rujukan dari penelitian yang dilakukan di Yogyakarta, penelitian ini juga mengkaji pustaka dari sebuah jurnal yang ditulis oleh Praditasari (2010). Dalam penelitiannya, penulis ini mengkaji peranan resepsionis dalam memberikan pelayanan prima kepada para wisatawan di Hotel Pramesthi Solo. Kajian pustaka yang terakhir dilakukan pada penelitian yang dilakukan oleh Wachidyah (2017). 
Dalam penelitiannya, disebutkan bahwa penelitian ini berjenis deskriptif untuk meninjau fungsi departemen front office, termasuk aktivitas resepsionis sebagai salah satu pilar penting dalam operasional hotel. Penelitian yang dilakukan melalui studi literatur ini kemudian menghasilkan kesimpulan bahwa departemen front office termasuk resepsionis adalah pilar utama dalam suatu bisnis hotel, di mana fungsi utamanya merupakan first and last impression from guest atau memberikan kesan pertama dan terakhir bagi tamu untuk hotel itu sendiri.

\section{Konsep}

Pada dasarnya, persepsi memiliki ruang lingkup cukup luas, menyangkut intern dan ektern. Berbagai ahli telah memberikan definisi yang beragam tentang persepsi, walaupun pada prinsipnya mengandung makna yang sama. Sebuah penelitian pada tahun 1990an menunjukkan bahwa persepsi merupakan elemen yang penting yang dapat mempengaruhi pilihan tujuan wisata bagi wisatawan (Kamenidou et al., 2009: 41).

Perkembangan selanjutnya, Zheithalm et al dalam Ariani (2009: 180) menyederhanakan dimensi di atas menjadi lima dimensi pokok yang dikenal dengan SERVQUAL (service quality) yang terdiri dari:

1. Bukti fisik (tangibles) yaitu kemampuan suatu perusahaan dalam menunjukkan eksistensinya kepada pihak eksternal. Penampilan dan kemampuan sarana dan prasarana fisik perusahaan yang dapat diandalkan serta keadaan lingkungan sekitarnya merupakan salah satu cara perusahaan jasa dalam menyajikan kualitas layanan terhadap pelanggan, yang meliputi fasilitas fisik (gedung, buku, rak buku, meja dan kursi), teknologi (peralatan dan perlengkapan yang dipergunakan), serta penampilan pegawai. 
2. Keandalan (reliability) adalah kemampuan perusahaan memberikan pelayanan sesuai dengan apa yang dijanjikan secara akurat dan terpercaya. Kinerja harus sesuai dengan harapan pelanggan yang tercermin dari ketepatan waktu, pelayanan yang sama untuk semua pelanggan tanpa kesalahan, sikap simpatik dan akurasi yang tinggi.

3. Daya tanggap (responsiveness) adalah kemauan untuk membantu pelanggan dan memberikan jasa dengan cepat dan tepat dengan penyampaian informasi yang jelas. Mengabaikan dan membiarkan pelanggan menunggu tanpa alasan yang jelas menyebabkan persepsi yang negatif dalam kualitas pelayanan.

4. Jaminan (assurance) adalah pengetahuan, kesopan-santunan dan kemampuan para pegawai perusahaan untuk menumbuhkan rasa percaya para pelanggan kepada perusahaan.

5. Empati (empathy) yaitu memberikan perhatian yang tulus dan bersifat individual atau pribadi yang diberikan kepada pelanggan dengan berupaya memahami keinginan konsumen dimana suatu perusahaan diharapkan memiliki suatu pengertian dan pengetahuan tentang pelanggan, memahami kebutuhan pelanggan secara spesifik, serta memiliki waktu pengoperasian yang nyaman bagi pelanggan.

\section{Metode Penelitian}

Penelitian ini dilakukan dengan menggunakan pendekatan penelitian kuantitatif dan kualitatif (mix method). Penelitian ini dilakukan terhadap setiap resepsionis dan juga wisatawan yang ada di Desa Munduk, Kecamatan Banjar, Kabupaten Buleleng, dengan menyasar seluruh akomodasi perhotelan yang ada di area ini. Jenis data yang digunakan adalah berupa kuantitatif dan kualitatif. Data kuantitatif diperoleh melalui distribusi kuesioner kepada responden wisatawan Eropa yang sedang atau sudah menginap di Desa Munduk. Kuesioner disebarkan kepada 100 
responden yang merupakan wisatawan Eropa yang menginap di Desa Munduk.

Pemilihan 100 responden ini dilakukan dengan metode purposive sampling dengan melihat data kedatangan wisatawan Eropa di Kabupaten Buleleng sebanyak 393.107 wisatawan mancanegara di mana 127.201 wisatawan di antaranya berasal dari Eropa (data Dinas Pariwisata Kabupaten Buleleng 2018). Dengan kendala keterbatasan waktu dari responden dan peneliti, dan dengan batasan bahwa sampel yang dipilih pernah menginap di akomodasi di Desa Munduk, maka dihitung jumlah sampel hanya berjumlah $1 \%$ dari total populasi, atau kurang lebih 100 orang.

Kemudian, data kualitatif didapatkan melalui hasil observasi, wawancara kepada wisatawan dan studi dokumentasi. Analisis data akan dilakukan secara deskriptif kualititatif dengan menerapkan beberapa teori yang relevan seperti teori persepsi dan perhitungan tentang indeks persepsi melalui skala Likert melalui metode kuesioner. Teori Persepsi (Mulyana, 2000) bahwa proses menangkap arti objek-objek sosial dan kejadiankejadian yang kita alami dalam lingkungan kita. setiap orang memiliki gambaran yang berbeda mengenai realitas disekelilingnya. Menurut teori Persepsi dari Mulyana (2000) bahwa terdapat lima jenis persepsi yakni: Persepsi berdasarkan pengalaman, selektif, dugaan, evaluatif dan kontekstual.

\section{Hasil Penelitian}

Data primer yang diperoleh langsung dari responden yaitu para wisatawan Eropa mengenai kualitas layanan resepsionis di Munduk, diperoleh melalui dua teknik pengumpulan data. Pertama melalui wawancara yang dilakukan langsung kepada para wisatawan, dan kedua 
melalui kuesioner yang diberikan kepada beberapa Para wisatawan Eropa yang sedang menginap.

Data sekunder yang kemudian melengkapi data primer, diperoleh dengan memanfaatkan data yang telah ada, misalnya laporan keluhan tamu (guest complaint) yang selama ini sudah ada di dalam internal hotel. Adapun kesepuluh hotel yang menjadi objek penelitian yang dikategorikan sebagai sepuluh besar akomodasi terbaik via situs online travel agent booking.com dalam data sekunder tersebut antara lain Puri Lumbung Cottages, Karang Sari Guest House, Made Homestay, Munduk Sari Nature, Manah Liang Bungalow, Waterfall Melanting Cottages, Arya Utama Garden Villas, Guru Ratna Homestay, Aditya Homestay, dan Puri Sunny Cottages. Data sekunder tersebut biasanya dapat ditemukan di departemen front office yang terdapat di hotel tersebut.

Berdasarkan data sekunder yang ditemukan di dalam hotel, yang diperoleh melalui studi dokumentasi dan observasi, jenis-jenis keluhan tamu yang sering ditemukan di resepsionis di Munduk, antara lain:

1) Kurangnya staff resepsionis dalam kecakapan berbahasa Inggris, utamanya pada ketampilan mendengarkan, menulis, dan berbicara.;

2) Rendahnya pemahaman staff resepsionis terhadap keluhan yang disampaikan berkaitan dengan atraksi wisata favorit di sekitar Desa Munduk.;

3) Perbedaan antara kondisi kamar yang sebenarnya dengan foto kamar tidur maupun kamar mandi yang ditampilkan di agen perjalanan.;

4) Adanya perbedaan jumlah tagihan pada mini bar antara yang dikonsumsi dengan apa yang tertera pada sistem

5) Terdapat staff resepsionis yang berargumen dengan tidak menggunakan etika (tamu menganggap staff tidak sopan)

Kelima jenis keluhan (guest complaint) tersebut memang yang paling sering ditemukan di akomodasi yang terdapat di Munduk. 
Disamping kelima jenis keluhan tersebut, masih banyak ditemukan jenis keluhan lainnya yang kerapkali dialami oleh turis. Sangat wajar karena bagian resepsionis menjadi wadah berkumpulnya keluhan dari tamu. Selain karena dianggap yang paling mudah diajak berkomunikasi, turis juga memperoleh kesan pertama maupun terakhir dari akomodasi, dari apa yang diperoleh melalui resepsionis. Tak jarang, di akomodasi yang terdapat di Munduk, mayoritas pemilik akomodasi masih turut campur tangan di departemen resepsionis.

Dari hasil penelitian melalui kuesioner, dengan menanyakan persepsi kualitas pelayanan resepsionis secara umum tergolong masih kurang baik. Dari 100 kuesioner yang disebar, 7\% responden memberikan persepsi sangat baik, kemudian $11 \%$ responden memberikan persepsi baik, lalu sekitar 30\% responden menyebutkan bahwa layanan resepsionis biasa saja. Kemudian sebanyak $29 \%$ responden memberikan pendapat bahwa layanan resepsionis masih kurang baik, sedangkan 23\% responden menyatakan bahwa layanan resepsionis masih sangat kurang baik. Penjabaran kelima indikator tersebut sebagai berikut.

Indikator Reliability yaitu: (1) Staff resepsionis memahami dengan jelas bentuk permintaan dari tamu, (2) Staff resepsionis mampu menjelaskan segala bentuk produk hotel, (3) Staff resepsionis mampu menjawab keluhan tamu dengan tepat dan akurat, (4) Staff resepsionis mampu memenuhi bentuk special request, (5) Staff resepsionis mampu berkomunikasi dengan bahasa Inggris atau bahasa asing Eropa lainnya

Indikator Responsiveness, yaitu: (1) Staff resepsionis selalu siap dalam menyediakan pelayanan dan menjawab pertanyaan, (2) Staff resepsionis dengan cepat dan tanggap menjawab pertanyaan tamu, (3) Staff dapat menjawab pertanyaan berkaitan dengan atraksi wisata di sekitar Munduk dan sekitarnya, (4) Seluruh informasi dan jawaban dapat dipercaya, (5) Staff masih bersikap sopan dalam situasi yang cukup sibuk 
Indikator Assurances, yaitu: (1) Turis selalu merasa aman dalam masa tinggalnya, (2) Turis merasa sangat aman dalam melakukan transaksi di kantor depan, (3) Informasi mengenai keuangan dan transaksi bisa dipercaya, (4) Seluruh informasi yang tersampaikan melalui kantor depan bisa tersampaikan dengan jelas, (5) Turis merasa nyaman dalam proses check in maupun check out.

Indikator Empathy, yaitu: (1) Staff resepsionis sangat peduli dengan hal-hal detail dari tamu, (2) Ketika tamu memberikan keluhan, resepsionis selalu berupaya memberikan solusi konkrit, (3) Sangat mudah bagi tamu untuk menghubungi resepsionis dalam situasi darurat, (4) Resepsionis mengerti dan memahami mengenai kebutuhan tamu dalam masa travelnya, (5) Pelayanan yang diberikan sesuai dengan harga yang dibayarkan.

Indikator Tangible, yaitu: (1) Fasilitas dan produk hotel memang cocok dan sesuai dengan apa yang terekam di Online Travel Agent, (2) Peralatan dan perlengkapan yang ada di lobby cukup memadai, (3) Fasilitas wifi cukup cepat dan mendukung aktivitas tamu, (4) Staff resepsionis berpenampilan baik dan sopan, (5) Staff resepsionis dilengkapi dengan fasilitas IT yang memadai.

\section{Pembahasan}

Dari hasil penelitian yang dilakukan, terdapat beberapa strategi utama yang harus dilakukan oleh pihak pengelola akomodasi wisata maupun stakeholder pariwisata di Munduk. Hal ini mestinya digunakan sebagai prioritas pembangunan mengingat dalam pengembangan destinasi di Bali Utara, aspek pembangunan kualitas sumber daya manusia seringkali diabaikan. Beberapa strategi tersebut antara lain:

1) Para pemilik akomodasi wisata hendaknya bekerjasama dengan akademisi atau lembaga pelatihan tenaga wisata untuk memberikan 
pelatihan resepsionis dan pelatihan bentuk lainnya dalam penyambutan tamu.

2) Para resepsionis di Munduk hendaknya rajin mencari ilmu baru, ataupun beradaptasi meningkat tingkat kunjungan wisata Eropa ke Munduk, dengan mulai mempelajari dan memahami bahasa utama para wisatawan.

3) Para agen perjalanan baik offline maupun online memberikan pelatihan bagi para resepsionis agar para resepsionis dapat melakukan update informasi mengenai akomodasi masyarakat lokal di Desa Munduk dengan terampil, untuk menghindari keluhan pelanggan.

4) Pemerintah melalui dinas pariwisata Kabupaten Buleleng dapat mengadakan pelatihan resepsionis dengan mengajarkan mengenai pentingnya tata kelola kantor depan yang profesional yang dibantu dengan teknologi informasi.

5) Para akademisi agar dapat menyelenggarakan pengabdian kepada masyarakat bagi para resepsionis dalam tata kelola dan manajemen mekanisme kerja, deskripsi pekerjaan, hingga Standard Operational Procedure (SOP) resepsionis di akomodasi perhotelan.

\section{Kesimpulan dan Saran}

Berdasarkan hasil dan pembahasan dari penelitian, dapat disimpulkan beberapa hal sebagai berikut. Pertama, persepsi tamu tentang pelayanan di akomodasi wisata yang terdapat di Munduk masih berada pada kondisi yang kurang baik. Kedua, aspek reliability dan tangible menjadi aspek yang paling menjadi sorotan dalam lima indikator kualitas pelayanan resepsionis di Munduk. Ketiga, sebagian besar keluhan pelanggan disebabkan oleh lemahnya proses manajemen hospitality yang dilakukan pemilik akomodasi, sehingga resepsionis perlu untuk diberikan pelatihan lebih lanjut. Keempat, pemilik akomodasi dan pengelola 
akomodasi hendaknya menyusun mekanisme kerja berikut dengan deskripsi kerja (job description) serta SOP (standard operational procedure) yang jelas dan tegas untuk menjamin perbaikan kualitas layanan resepsionis. Kelima, pmilik akomodasi seharusnya berkolaborasi dengan para stakeholder pariwisata di Munduk, baik pemerintah, agen perjalanan (offline dan online), para wisatawan, hingga akademisi untuk membangun bisnis pariwisata serta perhotelan yang lebih profesional.

Penelitian ini ingin memberikan sejumlah saran kepada beberapa pihak terkait. Pertama, para pemilik akomodasi wisata yang ada di Desa Munduk pada khususnya, dan di Kabupaten Buleleng pada umumnya agar dapat membuka diri, serta bekerjasama dengan akademisi atau lembaga pelatihan tenaga wisata untuk memberikan pelatihan resepsionis dan pelatihan bentuk lainnya dalam penyambutan tamu. Kedua, para karyawan khususnya di posisi resepsionis maupun posisi lainnya di akomodasi wisata yang ada di Munduk hendaknya rajin mencari ilmu baru, ataupun beradaptasi dengan mulai meningkatnya tingkat kunjungan wisata Eropa ke Munduk, dengan mulai mempelajari dan memahami bahasa utama para wisatawan. Ketiga, para agen perjalanan baik offline maupun online, utamanya yang saat ini cukup memperoleh komisi dalam penjualan kamar di Munduk, agar dapat membantu pemilik akomodasi dalam memberikan pelatihan bagi para resepsionis agar dapat melakukan update informasi mengenai akomodasi dengan terampil, untuk menghindari keluhan pelanggan. Keempat, pemerintah melalui dinas pariwisata Kabupaten Buleleng hendaknya secara berkala dapat mengadakan pelatihan resepsionis dengan mengajarkan mengenai pentingnya tata kelola kantor depan yang profesional yang dibantuk dengan teknologi informasi. Kelima, para akademisi dari pihak kampus agar dapat menyelenggarakan pengabdian kepada masyarakat, sebagai bagian dari Tri Dharma Perguruan Tinggi, bagi para resepsionis dalam tata kelola dan manajemen mekanisme 
kerja, deskripsi pekerjaan, hingga Standard Operational Procedure (SOP)

resepsionis di akomodasi perhotelan.

\section{Daftar Pustaka}

Abd El Jalil, S.J. (2010). Images of Egypt in United Kingdom Tour Operators' Brochures. Tourismos: An International Multidisciplinary Journal of Tourism, Vol. 5, No.2, pp.179-191.

Ariani, Dhorothea Wahyu. 2009. Manajemen Operasi Jasa. Penerbit Graha Ilmu. Yogyakarta

Arieta, Siti. 2010. Community Based Tourism Pada Masyarakat Pesisir: Dampaknya Terhadap Lingkungan dan Pemberdayaan Ekonomi. Jurnal Dinamika Maritim, Vol.2, No.1. Tersedia di http://riset.umrah.ac.id/

Budarma, I Ketut. 2011. "Syncretism Between Tourists' and Local Culture: the Impact of Tourism on Balinese Culture, Economy and Environment". Thesis. Angers: Université d'Angers

Dinas Pariwisata Provinsi Bali. 2013. Statistik Pariwisata Bali. Denpasar: Dinas Pariwisata Provinsi Bali

Kamenidou, I., Mamalis, S. \& Priporas, C. (2009). Measuring Destination Image and Consumer Choice Criteria: The Case Of Mykonos Island. Tourismos: An International Multidisciplinary Journal of Tourism, Vol. 4, No.3, pp.67-79.

Kasmir. 2005. Etika Customer Service. RajaGrafindo Persada. Jakarta

Leslie, David. 2012. Responsible Tourism: Concept, Theory and Practice. Massachusetts: CABI

MacKay, K.J. \& Fesenmaier, D.R. (2000). An Exploration of Cross-Cultural Destination Image Assessment. Journal of Travel Research, Vol. 38, pp.417423.

Meliou, E. \& Maroudas, L. (2010). Understanding Tourism Development: A Representational Approach. Tourismos: An International Multidisciplinary Journal of Tourism, Vol. 5, No.2, pp.115-127.

Mulyana, Deddy. 2000. Ilmu Komunikasi Suatu Pengantar. Bandung: PT. Remaja Rosdakarya.

Pitana, I Gde. 2002. Apresiasi Kritis Terhadap Kepariwisataan Bali. Denpasar: PT The Works

Pitana, I Gde. 2006. Kepariwisataan Bali dalam Wacana Otonomi Daerah. Jakarta: Puslitbang Kepariwisataan.

Praditasari, Onik. 2010. Peranan Resepsionis dalam Memberikan Pelayanan Prima di Hotel Pramesthi Solo. Jurnal 2010 Universitas Sebelas Maret Surakarta.

Rangkuti, Freddy. 2005. Analisis SWOT Teknik Membedah Kasus Bisnis. Jakarta: PT. Gramedia Pustaka.

Rukendi, Cecep dkk. 2008. Menanggulangi Kemiskinan Melalui Agrowisata dan Wisata Perdesaan yang Berkelanjutan. Jurnal Kepariwisataan Indonesia, Vo.3, No.4, hal. 503-510. Jakarta: Pusat Penelitian dan Pengembangan Kepariwisataan

Saleh, A Muwafik. 2010. Manajemen Pelayanan. Pustaka Pelajar, Jakarta. 
Saputro, Fandi. 2014. Aktivitas Recepsionist dalam Menangani Tamu Personal di Ameera Boutique Hotel Yogyakarta. Jurnal Khasanah Ilmu Vol. V No 2 September 2014.

Sunarto. 2007. Manajemen Ritel. Yogyakarta: Penerbit Amus.

Sunaryo, Bambang, 2013. Kebijakan pembangunan destinasi pariwisata konsep dan aplikasinya di Indonesia, Penerbit Gava Media, Yogyakarta, hal. 15.

Sutedja, Wira. 2007. Panduan Layanan Konsumen. Jakarta: PT. Grasindo

Tjiptono. 2012. Pemasaran Strategik. Yogyakarta : Penerbit ANDI.

Tjiptono, 2008. Service Management. Yogyakarta: Penerbit Andi

Wachidyah, Wiwin. 2017. Front Office Department dan Peranannya dalam Layanan Tamu Hotel. Jurnal Bisnis \& Teknologi Politeknik NSC Surabaya, Volume 4, Nomor 1, Juli 2017, ISSN : 2355 - 8865 \& E - ISSN : 2356 - 2544. 